\title{
A educação como ação norteadora e impulsionadora do desenvolvimento local
}

\section{Education as a guiding and driving action for local development}

\author{
Karen Giuliano Soares ${ }^{1}$ \\ Elaine Cristina Paganotti Rezende \\ Maria Augusta de Castilho \\ Ana Carla Fiirst dos Santos Porto
}

\begin{abstract}
Resumo: A finalidade do presente artigo foi à análise da relação existente entre à educação e o desenvolvimento local. Aplicou-se a metodologia de pesquisa exploratória, partindo-se do método analítico, a coleta de dados ocorreu por meio de informações secundárias, pesquisas bibliográficas em artigos científicos, livros e revistas. Procurou-se evidenciar um breve histórico da educação no Brasil, a importância da educação como ação norteadora do desenvolvimento local. Deu-se ênfase a educação dos agentes locais e sua realidade vivida sendo que o modo de refletir a vida e de adquirir conhecimentos não se encontra tão somente em uma sala de aula, como também na escola da vida, na própria realidade experimentada dia após dia pelos agentes locais. A pesquisa permitiu evidenciar a necessidade da educação como ação impulsionadora do desenvolvimento local, viabilizando vínculos importantíssimos para o adequado avanço e sustentação da localidade em que se experimenta e no que se deseja.
\end{abstract}

Palavras-chave: Educação. Desenvolvimento Endógeno. Desenvolvimento Local.

\begin{abstract}
The purpose of this article was to analyze the relationship between education and local development. The exploratory research methodology was applied, starting from the analytical method, data collection occurred through secondary information, bibliographical research in scientific articles, books and magazines. We sought to highlight a brief history of education in Brazil, the importance of education as a guiding action for local development. Emphasis was placed on the education of local agents and their lived reality. The way of reflecting life and acquiring knowledge is not only found in a classroom, but also in the school of life, in the reality experienced day after day. by local agents. The research made it possible to highlight the need for education as a driving action for local development, enabling very important links for the proper advancement and support of the place in which one experiences and desires.
\end{abstract}

Keywords: Education. Endogenous development. Local development

\section{Introdução}

A palavra 'desenvolvimento' está carregada de significados e se estende à diversas dimensões. O desenvolvimento local visa a união de uma determinada comunidade, fazendo aflorar suas próprias capacidades em prol de um objetivo em comum. Enfrentar seus limites, em busca de crescimento econômico, desenvolve a relação entre os indivíduos, empoderando-os e promovendo a inclusão social.

\footnotetext{
${ }^{1}$ Programa de Pós-Graduação em Desenvolvimento Local da UCDB
} 
Mesmo quando pautado do ponto de vista econômico, não pode-se deixar em segundo plano o fato do desenvolvimento local se tratar do próprio desenvolvimento humano.

Partindo da premissa de que o conhecimento é essencial no desempenho dos indivíduos e da formação da sociedade, percebe-se a íntima relação entre educação e desenvolvimento local.

Para tanto, é preciso fazer um breve histórico da educação no Brasil, que por sua vez, foi pautada através de Portugal. Nesse país, a maioria da população, bem como a pequena burguesia e até a família real, eram analfabetos, e houve a intervenção dos jesuítas para a formação educacional da alta administração pública.

No final do século XVIII, com a Revolução Industrial e o capitalismo crescente, os trabalhadores buscavam novas possibilidades, oferecendo mão-de-obra com maior potencial de trabalho.

Por sua vez, padres jesuítas se instalaram no Brasil afim de conduzir os costumes portugueses no espaço agora ocupado, buscando por uma organização do povoado brasileiro. No entanto, com a mudança de Governo português, o Brasil passou por um retardamento da educação, pois os jesuítas foram afastados e não havia mão-de-obra especializada para a educação.

Posteriormente, para melhor desempenho dos trabalhadores nas máquinas, iniciaram-se as instruções básicas para exercerem suas respectivas profissões, visando o desenvolvimento do país. As reformas que ocorreram no sistema de ensino, buscavam, também, a qualidade de vida dos trabalhadores.

Pode-se dizer que a educação é um dos pilares para o desenvolvimento, sendo que, o desenvolvimento local deve levar em consideração as relações que constituem o local e os atores ali inseridos, como protagonistas do processo.

O presente artigo visa destacar a relação entre educação e desenvolvimento local, buscando conceitos e pontos de vista de diversos autores, através de uma pesquisa exploratória, partindo-se do método analítico. A coleta de dados foi feita por meio de fontes secundárias, como artigos científicos, livros e revistas.

Para tanto, o trabalho está estruturado em 4 seções, sendo a Introdução para delinear o processo da pesquisa; o segundo capítulo fazendo um breve histórico da educação no país; o terceiro, por sua vez, visa refletir a educação como um entrelaçamento ao desenvolvimento local; e as Considerações Finais. 


\section{O início da educação no brasil: breve histórico}

A educação tem sido motivo de profundos desafios no decorrer dos anos. Vale ressaltar, nesse sentido, que a Revolução Industrial, ocorrida na Inglaterra, no final do século XVIII, estendeu-se até o Brasil, e impulsionou o desenrolar do ensino com a acelerada produção capitalista, viabilizando oportunamente, o início do deslocamento de um povoado que se apartava de suas raízes rurais primitivas, para cultivar uma nova fase de conquista por melhores condições de vida.

O Brasil, como os demais países da América Latina, apresentou intenso processo de urbanização, especialmente na segunda metade do século XX. Em 1940, a população urbana era de $26,3 \%$ do total. Em 2000 ela é de $81,2 \%$. Esse crescimento se mostra mais impressionante ainda se lembrarmos os números de absolutos: em 1940 a população que residia nas cidades era de 18,8 milhões de habitantes e em 2000 ela é de aproximadamente 138 milhões. Constatamos, portanto, que em sessenta anos os assentamentos urbanos foram ampliados de forma a abrigar mais de 125 milhões de pessoas. Considerando apenas a última década do século XX, as cidades brasileiras aumentaram em 22.718 .968 pessoas. Isso equivale a mais da metade da população do Canadá ou a um terço da população da França (MARICATO, 2011, p. 16).

No apogeu do capitalismo, com a oferta da mão de obra em alta, no perímetro urbano, artesãos e trabalhadores, sedentos por novas possibilidades que o capitalismo proporcionava, ofereciam mão de obra com empenho e potência de trabalho.

Trata-se de um gigantesco movimento de construção de cidade, necessário para o assentamento residencial dessa população bem como de suas necessidades de trabalho, abastecimento, transportes, saúde, energia, água etc. Ainda que o rumo tomado pelo crescimento urbano não tenha respondido satisfatoriamente a todas essas necessidades, o território foi ocupado e foram construídas as condições para viver nesse espaço [...] (MARICATO, 2011, p. 16).

Assim, verificou-se que as classes sociais, de forma precária, foram naturalmente identificadas e desassociadas do ensino, sendo ele profissionalizante ou não. O tempo dedicado aos estudos pertencia a um grupo social privilegiado pela Companhia de Jesus, que com condições diferenciadas dos demais grupos, despendiam tempo para se dedicar a um nível notável de polidez, influência e status. Leite (1973, p. 20) sustenta que:

Durante o primeiro século da sua existência, a ordem tornou-se uma corporação docente de influência e extensão até aí nunca vistas. Em 1640 tinha ela 521 colégios: 116 em Itália, 104 na Península Ibérica, 83 na Alemanha, 79 em França, 79 nos Países-Baixos, e 30 na Polônia. Além de suas próprias academias, universidades e colégios de instrução secundária, os jesuítas ocuparam cátedras em mais antigas instituições docentes. No meio do sec. XVIII, o ensino superior na Alemanha católica, nos Países-Baixos espanhóis, na Hungria, na Espanha, na França, na Itália, e no nosso país estava em grandíssima parte entregue à Companhia [...]. 
Portugal, país de importância ímpar para o entendimento das influências acerca da educação brasileira, teve intervenção dos jesuítas para a formação educacional da elite sacerdotal e da alta administração pública. A nobreza, guiada e favorecida por estudos de qualidade providos pelos jesuítas, atendiam nos mosteiros, estudiosos com capacidade intelectual elevada. Tais privilégios adquiriram significativa forma, organização e valor aos adeptos submetidos aos asilos das letras, dedicados ao conhecimento.

\begin{abstract}
Portugal, que até então vivera imerso na atmosfera medieval e ocupado com as intermináveis guerras santas contra os invasores mouriscos e guerras defensivas contra os espanhóis, começava apenas a despertar para a nova cultura da Renascença. Sem tradições educativas, o seu sistema escolar começava a esboçar-se mui vagamente apenas. $\mathrm{O}$ analfabetismo dominava não somente as massas populares e a pequena burguesia, mas se estendia até a alta nobreza e família real. Saber ler e escrever era privilégio de poucos, na maioria confinados à classe sacerdotal e à alta administração pública. É bem verdade que os mosteiros e as catedrais eram quase que os únicos asilos das letras, tanto sagradas como profanas; mas sua atuação era modesta e restrita à satisfação de suas necessidades internas; não tinham a consciência de estar cumprindo uma missão social (MATTOS, 1958, p. 37-38).
\end{abstract}

No Brasil, o método de ensino foi diferente, a educação fundada com a chegada dos portugueses e permanência da Coroa Portuguesa no território brasileiro teve como finalidade de direcionar e estabelecer aos nativos do povoado, o ensino de regras, dogmas e costumes inexistentes no espaço ocupado. Sendo assim, padres jesuítas, cúmplices da Corte Portuguesa, se instalaram no Brasil Colônia.

A Ordem dos Jesuítas é produto de um interesse mútuo entre a Coroa de Portugal e o Papado. Ela é útil à Igreja e ao Estado emergente. Os dois pretendem expandir o mundo, defender as novas fronteiras, somar forças, integrar interesses leigos e cristãos, organizar o trabalho no Novo Mundo pela força da unidade lei-rei-fé (RAYMUNDO, 1998, p. 43).

Nesse sentido, vislumbra-se que o consentimento da Coroa Portuguesa em permitir a influência dos jesuítas no Brasil foi estrategicamente articulada junto à Companhia de Jesus, já que a hierarquia superior observava a necessidade de organização do povo brasileiro, para que normas estabelecidas fossem digeridas pelos nativos de forma que o poder de convencimento fosse a melhor opção que a imposição.

[...] diversificada, com o objetivo de atender à diversidade de interesses e de capacidades. Começando pelo aprendizado do português, incluía o ensino da doutrina cristã, a escola de ler e escrever. Daí em diante, continua, em caráter opcional, o ensino de canto orfeônico e de música instrumental, e uma bifurcação tendo em um dos lados, o aprendizado profissional e agrícola e, de outro, aula de gramática e viagem de estudos à Europa (RIBEIRO, 1998, p. 21-22). 
Enquanto os jesuítas ensinavam os nativos a ler e a escrever, com a finalidade de compreender dogmas e envolvê-los no sentimento de pertença pela religião e pela hierarquia, do outro lado, também impulsionavam a elite permanente no Brasil, com relação aos estudos e formação.

Ambas as classes, de forma desigual, eram instruídas e impulsionadas para o porvir. Campos (1983, p. 69), destaca as diferenças que pairavam na sociedade:

\begin{abstract}
Em termos de sociedade, o mundo de antes de 1789 era marcado pela predominância do clero e da nobreza sobre as demais classes. Nobres e clérigos detinham privilégios datados da Idade Média: não pagavam impostos; quando cometiam algum crime eram julgados por tribunais especiais; recebiam dos governos pensões e mordomias várias. Para as camadas populares e a burguesia, a vida política no Antigo Regime apresentava-se muito limitada. Predominava o absolutismo de Direito Divino, regime no qual os reis concentravam nas mãos o poder que, segundo a tradição, recebiam de Deus.
\end{abstract}

Observa-se que o ensino transmitido pelos jesuítas aos nativos, se limitava as regras sedimentadas pelo catecismo, tendo como base e finalidade a formação religiosa, deixando-se de lado um método de ensino que proporcionasse aos natos, novas formas de pensar, agir e se conectar ao mundo.

Chegou, pois, ao século XIX, o costume de utilizar o catecismo para ensinar a ler, mesmo nas escolas oficiais, mas não deve ter ultrapassado muito as primeiras décadas. Persistindo como compêndio de formação religiosa, não resistiu à introdução de conceitos de civilidade, urbanidade e decência e à adaptação [...] (ANDRADE, 1978, p.16).

Dois séculos se passaram com o domínio e permanência do método educacional formulado pelos jesuítas, sendo que no século XVIII, Pombal assumiu o Governo do estado português, e constatou que o poder fiscalizador do estado se encontrava enfraquecido (VERÍSSIMO, 1961, p. 19).

De acordo com este autor, o governo metropolitano, viu a necessidade de proteção do governo absoluto que se sentia ameaçado pela igreja, "contudo, o governo absoluto tem uma necessidade suplementar: subordinar ao rei, a Igreja portuguesa, e em consequência, limitar ao máximo, a intervenção do Papa sobre ela" (VERÍSSIMO, 1961, p. 17).

Com o afastamento dos jesuítas do ensino por ordem de Marques de Pombal, e a mão de obra insuficiente de estudiosos aptos ao exercício e competência para educar, o Brasil passa por uma fase de decadência e retardamento da educação, e alcança deficiências e 
distintas formas de ensino com relação às classes sociais. Andrade (1978, p.114-115) enfatiza que:

\begin{abstract}
A Reforma baseou-se no princípio da substituição do método da Companhia de Jesus, por outro de índole mais simples e acessível, no que respeita as regras gramaticais, visto incidir sobretudo na disciplina central dos estudos secundários destes tempos - a Gramática Latina [...] As dificuldades britaram a flux, porque se tornava difícil conseguir livros apropriados e professores aptos que estivessem dispostos a seguir, com convicção, a nova ordem imposta. As primeiras edições dos compêndios quase se esgotaram em Lisboa e Província, recebendo o Brasil muito poucos, até se proceder a reimpressão [...].
\end{abstract}

No século XVIII, como já relatado no início da pesquisa, a Revolução Industrial exerceu seu apogeu no Brasil, e a mobilidade do povoado que outrora habitava na zona rural passa a ocupar o perímetro urbano de forma célere.

Mais tarde, para o fiel desempenho dos trabalhadores nas máquinas que exerciam o domínio nas indústrias, houve a necessidade de instrução básica para o exercício das profissões, sendo que passaram a ser de suma importância para o desenvolvimento do país.

Os investimentos na educação com a finalidade de ensino e aperfeiçoamento da população ganha motivação, e as escolas técnicas receberam o desafio de acelerar o progresso daquela gente.

Com o decorrer dos anos, verificaram-se sucessivas reformas ocorridas no ensino com a finalidade de uma melhor formação da população, com o fortalecimento do aprendizado não simplesmente para o exercício da mão de obra exigida pelas profissões, mas também para uma melhor qualidade de vida do indivíduo e da convivência em sociedade.

O Brasil, após a independência, percorreu longos anos com notáveis avanços distribuídos e previstos por meio das Constituições Brasileiras de 1824, 1891, 1934, 1937, 1946, 1967 e 1988, sendo que no século XX, com a promulgação da Constituição da República Federativa do Brasil de 1988, direitos sociais foram consagrados, sendo que um dos principais direitos sociais destacados foi o acesso à educação.

$\mathrm{O}$ artigo $6^{\circ}$, da Carta Magna considerou e determinou à educação como um direito social, sendo que dentre todas as constituições promulgadas no decorrer dos anos, esta foi a primeira a propor e considerar os direitos sociais ao povo brasileiro.

Para uma melhor organização de hierarquias, mais adiante, por meio do art. 22 XXIV, a Carga Magna determina "a competência privativa à União legislar sobre diretrizes e bases 
da educação nacional”. Para tanto, a Lei no 9.394, de 20 de dezembro de 1996, estabeleceu diretrizes e bases da educação nacional:

\begin{abstract}
Art. $1^{\circ}$ A educação abrange os processos formativos que se desenvolvem na vida familiar, na convivência humana, no trabalho, nas instituições de ensino e pesquisa, nos movimentos sociais e organizações da sociedade civil e nas manifestações culturais.

$\S 1^{\circ}$ Esta Lei disciplina a educação escolar, que se desenvolve, predominantemente, por meio do ensino, em instituições próprias.

$\S 2^{\circ} \mathrm{A}$ educação escolar deverá vincular-se ao mundo do trabalho e à prática social. Art. $2^{\circ}$ A educação, dever da família e do Estado, inspirada nos princípios de liberdade e nos ideais de solidariedade humana, tem por finalidade o pleno desenvolvimento do educando, seu preparo para o exercício da cidadania e sua qualificação para o trabalho (BRASIL,1996).
\end{abstract}

Mais adiante, a Lei Maior, por meio de seu artigo 23, V, determinou que "é de competência comum da União, dos Estados, do Distrito Federal e dos Municípios proporcionar os meios de acesso à cultura, à educação, à ciência, à tecnologia, à pesquisa e à inovação”. Dessa forma, para atender de forma eficaz a Constituição, promulgou-se em 1996, a Lei de Diretrizes e Bases de Educação Nacional.

Os desafios continuam, pois progredir para que a educação cumpra seu papel é um processo longo, desafiador e delicado, e para que as articulações exerçam o fiel desempenho designado pela Constituição (1988) precisa-se de líderes competentes, interessados e mobilizados a favor da tomada de decisões adequadas e estrategicamente designadas, o que conferirá sentido à educação e a satisfação do direito social destacado.

\title{
A educação como ação norteadora e impulsionadora do desenvolvimento local
}

No Brasil, pode-se evidenciar que desde as últimas décadas do século XIX, na literatura do país, os estudos relacionados à educação e desenvolvimento sempre estiveram em evidência, demostrando a devida relevância da educação, ensino e instrução, considerados elementos fundamentais ao processo de desenvolvimento de uma sociedade, tanto nas fases de bonança quanto nos momentos desastrosos e desafiadores (PIRES, 2005).

Assim, percebe-se desde cedo, que a educação sustenta o desenvolvimento de uma nação, e, até mesmo, de um pequeno povoado, e, é por meio dela, que o progresso acontece sucessivamente e se expande progressivamente. $\mathrm{Na}$ análise em evidência acerca da educação e do desenvolvimento, verifica-se a importância do capital humano que interage e integra a educação formal com a educação informal, estabelecendo um papel fundamental para o 
desenvolvimento econômico e social de um local, sendo que quando se tem níveis de educação mais altos, existe também maior produtividade, o que eleva a taxa do Produto Interno Bruto de um país (PIB), contribuindo e agregando no crescimento econômico da sociedade (SOUZA, 2004).

De acordo com Schultz (1973), o capital humano tem uma particularidade, o fato de que ele parte do homem, tendo em vista que o humano está configurado no homem, e ainda considera-se o capital, pois é compreendido como fonte de satisfações e ou rendimentos futuros. O autor supracitado parte do pressuposto de que educação é um investimento, que posteriormente pode gerar receitas ao indivíduo, e relaciona-se a economia.

Ainda de acordo com Schultz (1973), o capital humano é de suma importância para o desenvolvimento de uma sociedade, uma vez ser o esforço humano, o trabalho produzido pelo homem de forma natural e sem interferências externas, àquele que faz parte do ser-humano, e que necessita simplesmente dele para produzir e transformar o meio em que habita, apto para possibilitar satisfações e render frutos. O mesmo autor evidencia que a educação junto com capital humano promove investimentos de grande valia ao indivíduo, a comunidade, e ao país como um todo, permitindo o movimento da economia e a metamorfose de uma geração.

Pode-se observar que no decorrer de longos anos, o capital humano tem manifestado importância ímpar para o desenvolvimento econômico, social e cultural, sendo considerado elemento fundamental do conhecimento, uma vez ser parte do processo direcionador e impulsionador da forma de educar. É por meio dos conhecimentos vinculados às habilidades, experimentações, tentativas e ensaios realizados pelos indivíduos, que se solidificam teorias agregadoras de um processo capaz de gerar reflexão e aplicação de métodos capazes de possibilitar inovações e progressos nos locais, procurando atender as necessidades de seu povo.

No mesmo norte, Carvalho e Souza (1999) afirmam que o capital humano é a capacidade, o conhecimento, a habilidade, a criatividade e as experiências que um indivíduo possui e que o permite fazer a diferença no lugar em que se encontra inserido,-sendo propulsor de um dos pilares do capital intelectual, amplamente estudado e difundido na sociedade do conhecimento.

Dowbor (2007, p. 86), corrobora que a aprendizagem continuada aprofunda "a transformação da cronologia do conhecimento: a visão do homem que primeiro estuda, depois trabalha, e depois se aposenta torna-se cada vez mais anacrônica", ou seja, reitera a 
necessidade de uma educação continuada, que acompanha o indivíduo ao longo dos anos e contribui para o seu processo de desenvolvimento de forma plena, aprimorando suas competências e habilidades.

Vale ressaltar que, quando se menciona a importância da educação para o desenvolvimento, como também do capital humano, como instrumento capaz de gerar e agregar valor no local, faz-se necessário evidenciar o Índice de Desenvolvimento Humano IDH, que é essencial para o desenvolvimento da localidade, superabundando a relação existente entre a educação e o Desenvolvimento Local. Nesse contexto, Albagli e Maciel (2004), destacam que as dinâmicas cognitivas, informacionais, inovativas e socioespaciais, são indissociáveis e imperativas na argumentação.

No sistema de relações que configuram o ambiente local, a dimensão cognitiva dos
atores - expressa em sua capacidade de tomar decisões estratégicas e em seu
potencial de aprendizado e inovação - é determinante de sua capacidade de
capitanear os processos de crescimento e mudança, ou seja, de desenvolvimento
local. (BARQUERO 1999, apud ALBAGLI; MACIEL, 2004, p. 11).

Nas discussões sobre Educação e Desenvolvimento Local, pode-se considerar as relações que constituem o local, a grandeza do processo de adquirir conhecimento, seja por meio da memória, pensamento, raciocínio, percepção, linguagem, dentre outros elementos nos quais estão envolvidos os atores locais, que determinam sua capacidade de tomar decisões, de serem protagonistas do seu potencial produtivo, de aprendizagem, inovação e transformação.

Dowbor (2006, p. 01) corrobora com essa discussão destacando que:

A região de São Joaquim, no sul do Estado de Santa Catarina, era uma região pobre, de pequenos produtores sem perspectiva, e com os indicadores de desenvolvimento humano mais baixo do Estado. Como outras regiões do país, São Joaquim, e os municípios vizinhos, esperavam que o desenvolvimento "chegasse" de fora, sob forma do investimento de uma grande empresa, ou de um projeto do governo. Há poucos anos, vários residentes da região decidiram que não iriam mais esperar, e optaram por uma outra visão de solução dos seus problemas: enfrentá-los eles mesmos. Identificaram características diferenciadas do clima local, constataram que era excepcionalmente favorável à fruticultura. Organizaram-se, e com os meios de que dispunham fizeram parcerias com instituições de pesquisa, formaram cooperativas, abriram canais conjuntos de comercialização para não depender de atravessadores, e hoje constituem uma das regiões que mais rapidamente se desenvolve no país. E não estão dependendo de uma grande corporação que de um dia para outro pode mudar de região: dependem de si mesmos.

Portanto, pode-se observar que em um estudo mais aprofundado acerca do desenvolvimento local, existe um conceito específico, importante e muito utilizado pelos pesquisadores estudiosos do âmbito interdisciplinar de desenvolvimento local, a denominação que se utiliza para as iniciativas dos agentes locais que ocupam uma área e interagem entre si 
utilizando-se de suas capacidades, habilidades, conhecimentos, e participando ativamente do processo de mudança de uma comunidade é designado como 'desenvolvimento endógeno', ou seja, aqueles procedimentos que acontecem por meio de iniciativas daqueles que conhecem as necessidades do local em que se encontram inseridos.

Verifica-se que as forças do local e da sua coletividade, contribuem para o desenvolvimento local endógeno que, segundo Ávila (2003), tem como perspectiva as competências e habilidades da comunidade local, pois dessa forma a comunidade começa a assumir o seu próprio processo de desenvolvimento.

Contudo, as relações existentes entre educação e desenvolvimento local se vinculam diretamente com a necessidade de formar seres humanos que possam transformar o local onde se encontram inseridos, possibilitando a transmissão de um intenso sentimento de pertença nas dinâmicas construtivas da população, uma vez que muitas das vezes os jovens e demais indivíduos da comunidade desconhecem a origem da rua onde moram e até os potenciais do subsolo da região onde se criaram, não tem informação e interesse pelas forças e fraquezas, e/ou oportunidades e ameaças da comunidade a qual pertence (DOWBOR, 2006).

Segundo Albagli e Maciel (2004), o conhecimento sobre a comunidade local e suas necessidades ou potencialidades são essenciais, pois modifica o território a partir de suas características e atributos, contribuindo para uma valorização econômica, ao passo que promove o desenvolvimento sustentável.

Para uma cidadania ativa, vale enfatizar a imprescindibilidade da informação e do conhecimento, pois só assim pode haver transformações. A educação, nesse viés, não deve ser um trampolim para um indivíduo sair de sua região, mas, um auxílio no processo de transformação da pessoa e da comunidade local onde está introduzido (IDEM).

Ávila (2012) destaca que há uma dupla relação entre desenvolvimento local e educação (endógeno-emancipatório), que conota como causa e efeito, de forma recíproca e alternando-se. Dessa forma, inicialmente, se educa formativamente para o desenvolvimento local, e de forma contínua, a dinâmica do desenvolvimento local forma o processo efetivo e altamente educativo para a personalizada e sociocomunitarizada cidadania de todas as pessoas envolvidas, sendo assim, os dois elementos dessa dupla relação se retroalimentam de forma alternada.

Esse mesmo autor destaca que essa relação vai ao encontro do art. 22, da Lei n ${ }^{\circ}$ 9.394, de 1996 da Lei de Diretrizes e Bases da Educação Nacional, quando frisa a expressão 
'desenvolver o educando', como a primeira das três finalidades da Educação Básica: “A educação básica tem por finalidades desenvolver o educando, assegurar-lhe a formação comum indispensável para o exercício da cidadania e fornecer-lhe meios para progredir no trabalho e em estudos posteriores" (BRASIL, 1996).

Diante das desigualdades econômicas, sociais e culturais no Brasil, um aspecto de fundamental importância é a educação, equiparada entre à educação formal apresentada pelas instituições de ensino à educação informal, de tal forma que os indivíduos possam ser agentes transformadores do mundo em que vivem.

De acordo com Libaneo (1994), a educação tem por finalidade, prover às pessoas conhecimentos e experiências culturais que as tornem aptas a operar no meio social e possam transformá-lo, tendo em vista as necessidades econômicas, sociais e políticas da comunidade local, que consigam ser protagonistas do processo de desenvolvimento da sociedade.

Segundo Dowbor (1998, p. 259), "pela primeira vez a educação tem a possibilidade de ser determinante sobre o desenvolvimento", sendo que quando as instituições de ensino deixam de ser lecionadoras e passam a ser protagonistas na difusão e gestão do conhecimento, visto que na sociedade atual o conhecimento está na centralidade das discussões, os desafios saem do papel e se transformam em realidade, pois, "trata-se não só de adquirir o conhecimento, mas de assegurar a sua reprodução, circulação, generalização nos diversos setores da sociedade." (DOWBOR, 2001, p. 62).

Mais importante do que aprender é poder compartilhar os ensinamentos de tal forma que seja possível a transformação dos mais variados contextos de uma sociedade. O processo de desenvolvimento está relacionado, nesse sentido, à capacidade do indivíduo em transformar informação em conhecimento e modificar a comunidade local.

A educação é fundamental no desempenho das pessoas e da sociedade moderna, estimula a criatividade, a inovação e faz parte das economias modernas, baseada no capital intelectual como centro do processo de desenvolvimento.

Nascimento (2001) corrobora que educação e desenvolvimento são temas integrados, sempre apresentados juntos, são processos articulados, um se remete ao outro, no entanto, ambos têm suas próprias especificidades.

A educação enquanto investimento deve ir além dos benefícios individuais, deve abranger os interesses coletivos, contribuindo para melhorias na sociedade como um todo, 
dessa forma, os ganhos sociais provenientes da educação podem ser considerados como externalidades positivas.

Nessa perspectiva, os "spillovers do conhecimento são importantes para a sustentabilidade do crescimento endógeno dadas as externalidades positivas e traduzem-se na promoção e na difusão do conhecimento, com impactos diretos ao nível da produtividade" (CORREIA e PEREIRA 2006, p. 71).

De acordo com Canário (2013), o desenvolvimento local tem como perspectiva processos educativos, globalizados a nível local, com enfoque de aprendizagem, valorizando conhecimento e experiências locais.

Cabe destacar o conhecimento tácito, aquele aprendido ao longo dos tempos, no cotidiano, nos saberes locais, que passam de geração para geração. Não menos importante que o saber científico, dessa forma, levar as pessoas a confiarem em si mesmas, no seu potencial, melhorando a autoestima dos indivíduos e grupos, é uma reconstrução dos saberes, uma responsabilidade dos agentes externos do desenvolvimento local, onde para enfrentar esta questão da descrença, há todo uma aspecto do trabalho local virado a este ganho de confiança, de autoestima e que passa, fundamentalmente, por projetos e pelos pequenos/ grandes sucessos que vão obtendo.

Um novo olhar para educação nos dias de hoje, tem se destacado, e está intrinsicamente relacionado ao desenvolvimento local, a visão de que o aluno deve ter um papel ativo no seu processo de aprendizagem, o professor passar a ser mediador do processo e não mais transmissor do conhecimento, valorizando assim o conhecimento e o potencial de cada aluno de ser protagonista no processo de transformação pessoal e também do local em que vivem.

\section{Considerações finais}

Quando socializa os indivíduos, desenvolvendo atitudes e hábitos cordiais entre eles, a educação se mostra fundamental em todas as esferas do desenvolvimento. Ao passo que, o desenvolvimento local prega o protagonismo e as habilidades afloradas de uma determinada comunidade, pode-se dizer que a educação é propulsora nesse processo. 
Vista como um pilar para o desenvolvimento local, a educação transforma a visão dos indivíduos, unindo-os por uma mesma causa, ao mesmo tempo em que fortalece as relações dos grupos, permitindo uma ativa participação do cidadão.

Vale destacar que, sem a educação, o processo de desenvolvimento não seria possível, visto que não haveria respeito e socialização entre os indivíduos, fazendo com que um queira se sobressair mais do que outro. E o processo de desenvolvimento visa coletividade e mobilização, buscando crescimento.

Ora, se o desenvolvimento local é fortalecimento (das relações sociais), crescimento (de determinada comunidade), evolução (no viés econômico, por exemplo), dentre outras dimensões, então a educação permeia todo o processo evolutivo, fazendo parte do capital humano.

Observou-se a intrínseca relação entre educação e desenvolvimento local, concluindo-se que esse termo é interdisciplinar e, portanto, resultado da soma de esferas diversas, em busca do correto desenvolvimento endógeno.

\section{Referências}

ALBAGLI, Sarita; MACIEL, Maria Lúcia. Informação e conhecimento na inovação e no desenvolvimento local. Ciência da Informação, Brasília, n. 3, v. 33, p.9-16, set./dez. 2004. ANDRADE, Antônio Alberto Banha. A reforma pombalina dos estudos secundários no Brasil. São Paulo: Saraiva, Universidade de São Paulo, 1978.

ÁVILA, Vicente Fideles De. Dupla relação entre educação e desenvolvimento local endógeno-emancipatório. RAIDEIA - Revista do curso de pedagogia da universidade FUMEC. n. 12, v. 9, p. 13-49, jan./jun. 2012. Disponível em:

$<$ http://www.fumec.br/revistas/paideia/article/view/1578/988>. Acesso em 22 ago.2019.

ÁVILA, Vicente Fideles de. Educação escolar e desenvolvimento local: realidade e abstrações no currículo. Brasília: Plano Editora, 2003.

BRASIL. Lei n. 9.394, de 20 de dezembro de 1996. Estabelece as diretrizes e bases da educação nacional. Diário Oficial da União, 23 dez. 1996. Disponível em:

$<$ http://portal.mec.gov.br/seed/arquivos/pdf/tvescola/leis/lein9394.pdf\%3E > . Acesso em: 27 ago. 2019.

CAMPOS, Raymundo. História do Brasil. São Paulo: Atual, 1983.

CANÁRIO, R. Educação de Adultos: Um Campo e uma Problemática. Lisboa: Educa, 2013. CARVALHO, Ana Cristina Marques de, SOUZA, Leonardo Pellegrino de. Ativos intangíveis ou capital intelectual: discussões da contradição na literatura e proposta para sua avaliação. Em: Prescpect. Cienc. Inf., Belo Horizonte, v.4, n.1, p.73-83, jan./jun. 1999.

CORREIA, I. M.; PEREIRA, O. P. Spillovers do conhecimento e desenvolvimento regional: evidência de Portugal. Revista Portuguesa de Estudos Regionais, n.3, p. 67-82. 2006. 
DOWBOR, Ladislau. A reprodução social. São Paulo, 2001. Disponível em:

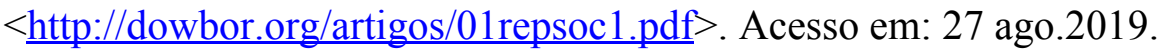

DOWBOR, Ladislau. Educação e Desenvolvimento. São Paulo, 2006. Disponível em:

$<$ http://dowbor.org/2006/04/educacao-e-desenvolvimento-local-doc.html/>. 22 ago.2019.

DOWBOR, Ladislau. Educação e apropriação da realidade local. Estudos Avançados.

[online]. v.21, n.60, p.75-90. São Paulo, 2007. Disponível em:

$<$ http://www.scielo.br/scielo.php?pid=S0103-40142007000200006\&script $=$ sci abstract\&tlng $=\mathrm{pt}>$. 22 ago.2019.

DOWBOR, Ladislau. A reprodução social. São Paulo, Vozes, 1998.

EDUCAÇÃO. 2011. Disponível em

$<$ http://www.brasil.gov.br/educacao/2011/10/surgimento-das-escolas-tecnicas $>$. Acesso em

10 nov.2019.

LEITE, Bazilisso. Generalidades das missões jesuíticas: roteiro histórico e turístico. 2 ed.

Porto Alegre: A 4 LTDA, 1973.

LIBANEO, José Carlos. Didática. São Paulo: Cortez, 1994.

MARICATO, Erminia. Brasil, cidades: alternativas para a crise urbana. 5. ed. Petrópolis: RJ: Vozes, 2011.

MATTOS, Luiz Alves de. Primórdios da educação no Brasil: o período heróico (15491570). Rio de Janeiro: Aurora, 1958.

NASCIMENTO, E. P. Educação e desenvolvimento na contemporaneidade: dilema ou desafio. In: Ciência, ética e sustentabilidade: desafios ao novo século p. 95-114. Distrito

Federal: Unesco, 2001

PIRES, V. Economia da Educação: para além do capital humano. São Paulo: Cortez, 2005.

RAYMUNDO, Gislene Miotto Catolino. Os princípios da modernidade nas práticas educativas dos jesuítas. 1998. 143 fl. Dissertação (Mestrado). Universidade Estadual de Maringá, Paraná, 1998.

RIBEIRO, Maria Luisa Santos. História da educação brasileira: a organização escolar. 15. ed. Campinas: Autores Associados, 1998.

SCHULTZ, T. W. O Capital Humano: Investimentos em Educação e Pesquisa. Rio de Janeiro: Zahar Editores, 1973.

SOUZA, M. R. P. de. Fatores determinantes do crescimento das regiões: um processo de mensuração. 2004. 161f. Tese - Programa de Pós-Graduação em Engenharia de Produção, Universidade Federal de Santa Catarina. Florianópolis, 2004.

VERRISSIMO, Ignácio José. Pombal, os Jesuitas e o Brasil. Rio de Janeiro, RJ: Imprensa do Exército, 1961. 